\section{A lobulated mass on the upper back with prominent vascula- ture: A giant basal cell carcinoma}

\author{
Elysha M. Kolitz, ${ }^{1}$ Brian L. Scott, ${ }^{2}$ \\ Travis Vandergriff, ${ }^{3}$ Melissa Mauskar ${ }^{3,4}$ \\ ${ }^{1}$ UT Southwestern Medical School, \\ Dallas, TX; ${ }^{2}$ Oregon Health \& Science \\ University, Portland, OR; ${ }^{3}$ Department \\ of Dermatology, UT Southwestern \\ Medical Center, Dallas, TX; \\ ${ }^{4}$ Department of Obstetrics and \\ Gynecology, UT Southwestern Medical \\ Center, Dallas, TX, USA
}

\begin{abstract}
Basal cell carcinoma (BCC) is characterized by slow but locally invasive growth. Although there is low metastatic potential, if not treated early, these skin cancers can lead to significant morbidity and mortality. In this case report, we present a man with a neglected BCC that developed into what is termed a giant $\mathrm{BCC}$ or one that is greater than $5 \mathrm{~cm}$. This tumor was discovered only upon workup of orthostatic lightheadedness and iron deficiency anemia. Although rare, basal cell carcinoma must be included on the differential of a large cutaneous lesion and may be a source of significant blood loss.
\end{abstract}

\section{Introduction}

Basal cell carcinoma (BCC) is characterized by slow but locally invasive growth, a low metastatic potential, and a pearly pink appearance on physical exam. ${ }^{1}$ Giant basal cell carcinoma is the term used to describe a BCC greater than $5 \mathrm{~cm} \cdot{ }^{1-3}$ Most basal cell carcinomas are small lesions with only $0.5 \%$ meeting the size criteria for a giant lesion. ${ }^{4}$ Giant basal cell carcinomas are most common in elderly males and show a predilection for the head, neck, and upper back. ${ }^{1,3,5}$ We present a man with symptomatic iron deficiency anemia caused by a giant BCC.

\section{Case Report}

A 60-year-old Caucasian male with no personal history of skin cancer, immunosuppression, or radiation exposure presented to the emergency department for assessment of a three-day history of fatigue and orthostatic lightheadedness. The patient had a history of essential hypertension treated with metoprolol but no other known chronic medical conditions. His initial labs were notable for a hemoglobin of 7.2 (reference 13.2-16.9 g/dl), mean corpuscular volume of 73.6 (reference 76.2-98.6 femtoliters), ferritin of 6 (reference $30-400 \mathrm{ng} / \mathrm{ml}$ ), and unsaturated iron binding capacity of 371 (112-346 mcg/dl), consistent with iron deficiency anemia. On exam, he was found to have a $15 \times 10 \times 4 \mathrm{~cm}$ firm, fungating, lobulated, violaceous-pink tumor with areas of ulceration leaking serosanguinous fluid on his upper back (Figure 1). Along the surface of the tumor and extending inferolaterally into the peritumoral skin were radiating dilated violaceous vessels. Extending beyond the dominant growth was a rim of violaceous-pink patches. The total area of skin involvement (combining both the excrescence and rim of involved tissue) was $20 \times 18 \mathrm{~cm}$. Upon further questioning, the patient stated that the mass had been present and slowly enlarging for 18 years. On computerized tomography, the mass was found to be heterogeneously enhancing involving the skin and subcutaneous fat overlying the trapezius muscle with no bony or visceral involvement. The patient's lesion was excised primarily by surgical oncology leaving exposed left scapula, trapezius, spinous processes, and occipital fascia (Figure 2). Excisional margins were noted as less than $2 \mathrm{~mm}$ from the deep margin and greater than $2 \mathrm{~cm}$ from all other margins. Microscopic examination of the tumor specimen demonstrated dermal nodules of pleomorphic, hyperchromatic purple cuboidal and columnar cells with scattered keratin pearls in a background of loose fibrous stroma and a moderate lymphocytic infiltrate, consistent with a diagnosis of BCC (Figure 3). Two weeks later, plastic surgery performed a rotational skin flap from suboccipital region and split thickness skin grafting from lower back to upper back wound. This patient had no additional treatments.

\section{Discussion}

Prior to this case, approximately 14 cases of basal cell carcinomas greater than or equal to $20 \mathrm{~cm}$ have been reported in the literature. ${ }^{4,6-10}$ When they exceed $20 \mathrm{~cm}$, they are termed super giant BCCs. ${ }^{7}$ The primary cause of a giant BCC is attributable in the majority of cases to either tumor neglect or local recurrence of a previously treated lesion. ${ }^{4,6-10}$ Relative to smaller tumors, giant BCCs are more likely to be of a histologically aggressive subtype (morpheaform,
Correspondence: Melissa Mauskar, UT Southwestern Medical Center, Department of Dermatology, 5939 Harry Hines Blvd, Suite 400, Dallas, TX 75390-9069, USA.

E-mail: melissa.mauskar@UTSouthwestern.edu

Key words: Basal cell carcinoma, giant, super giant, cutaneous neoplasm, hedgehog inhibitors

Contributions: Elysha Kolitz and Brian Scott wrote the manuscript, Travis Vandergriff provided pathology and diagnosis, and Melissa Mauskar was the treating physician. All authors reviewed and contributed to this paper.

Conflict of interest: The authors declare no potential conflict of interest.

Funding: None

Ethical approval and consent to publication: Written consent was obtained from the patient.

Availability of data and materials: Data available from the authors.

Please cite this article as: Kolitz EM, Scott BL, Vandergriff T, Mauskar M. A lobulated mass on the upper back with prominent vasculature: a giant basal cell carcinoma. Dermatol Rep 2021;13:9046.

Received for publication: 10 December 2020. Revision received: 8 February 2021.

Accepted for publication: 11 February 2021

This work is licensed under a Creative Commons Attribution-NonCommercial 4.0 International License (CC BY-NC 4.0).

${ }^{\circ}$ Copyright: the Author(s), 2021

Licensee PAGEPress, Italy

Dermatology Reports 2021; 13:9046

doi:10.4081/dr.2021.9046

micronodular, metatypical) and are more likely to recur following simple excision. ${ }^{1,3}$ In contrast to the very low metastatic incidence of BCCs overall $(0.03 \%)$, the rate has been reported to be as high as $45 \%$ in tumors greater than $10 \mathrm{~cm}$ and $100 \%$ in tumors greater than $25 \mathrm{~cm} .{ }^{11}$ The most common sites of metastasis are the lymph nodes and lungs, with a mean survival after metastatic spread of only $8-14$ months..$^{11,12}$ Although minor bleeding has been associated with BCCs secondary to tissue friability common to these neoplasms, only 10 cases of acute or chronic anemia subsequent to giant BCC have been reported. ${ }^{6}$

Wide and deep surgical excision is the mainstay curative treatment of giant BCC. ${ }^{13}$ The ideal margin size for large $\mathrm{BCC}$ is unknown given the rarity of the tumor, but 


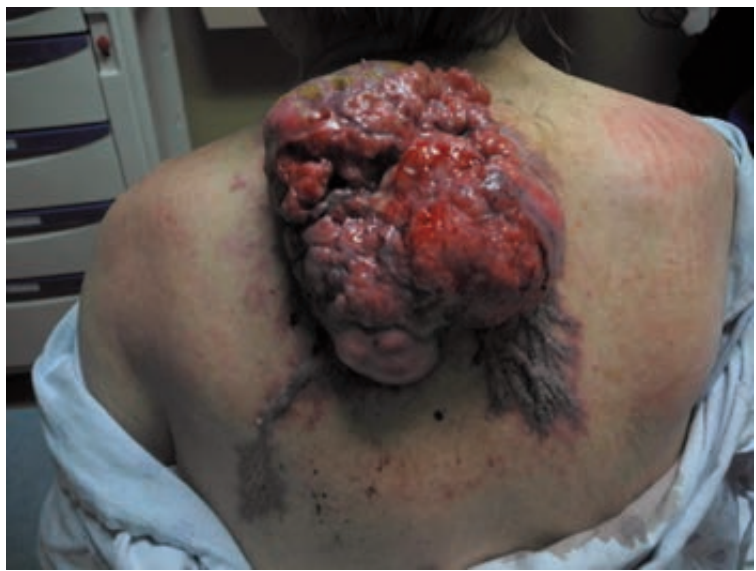

Figure 1. Clinical photograph. Gross view of mass on upper back demonstrating the pink-violaceous, lobulated, shiny surface with prominent vasculature extending from the inferolateral surfaces.

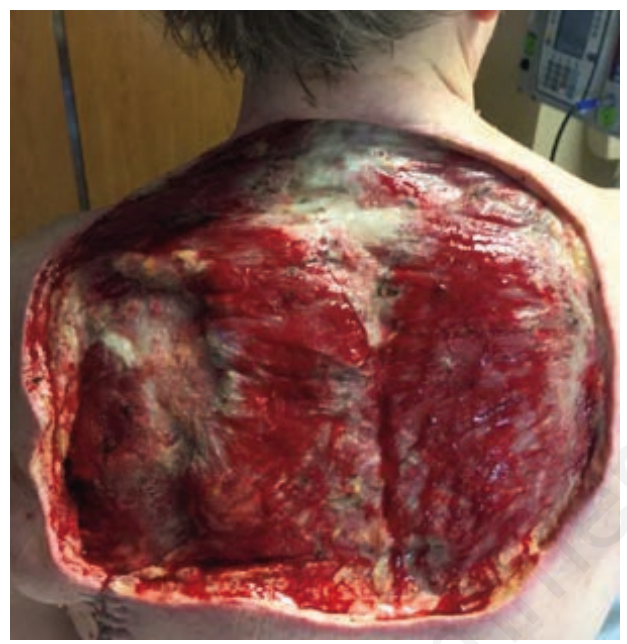

Figure 2. Clinical photograph. Gross view of upper back after surgical excision of mass demonstrating a large defect with exposed musculature.

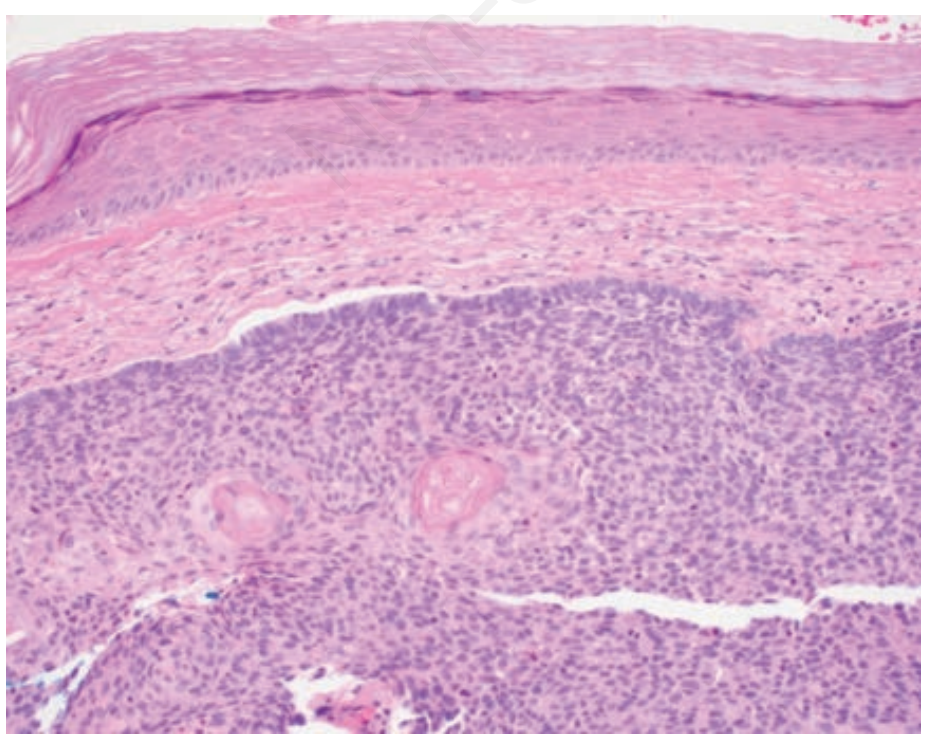

Figure 3. Skin histopathology. Hematoxylin \& Eosin stain of a shave biopsy specimen at $100 \times$ magnification demonstrating a basaloid nodule in the dermis, with peripheral palisading of nuclei and retraction between tumor and stroma. recommendations vary from $5 \mathrm{~mm}$ to 1 cm. ${ }^{2,4-5,13}$ Mohs micrographic surgery offers the advantage of assessing for residual tumor at the time of operation and has been recommended as the treatment of choice for lesions in cosmetically sensitive regions. ${ }^{2,14}$ Additional treatments can be considered including oral treatment with hedgehog pathway inhibitors, vismodegib and sonidegib, approved in 2012 for those with locally advanced, metastatic, or inoperable BCC. ${ }^{15}$ Vismodegib has been shown to have an overall response rate of $43 \%$ in locally advanced diseases and has been reported to be effective in giant basal cell carcinomas. ${ }^{4,16}$ Treatment can be therapeutic or neoadjuvant, with a successful case demonstrating a giant BCC treated with vismodeg$\mathrm{ib}$ as a debulking agent prior to surgery. ${ }^{17}$ However, another study documented that although there may be reduction in the cutaneous lesion of the giant $\mathrm{BCC}$, there was no reduction in the deeper tumor plane, and the patient still required adequate deep margins. ${ }^{18}$ Furthermore, usage of this drug may be challenging secondary to tumor resistance, the side effect profile, and recurrence after cessation of the drug. ${ }^{18-20}$ Other considerations must be taken into account when prescribing hedgehog inhibitors, including patient compliance. Monitoring a patient's response to treatment is essential in the case of a giant BCC. ${ }^{18} \mathrm{~A}$ patient who is at risk for non-compliance, such as those with giant BCCs, may not be ideal candidates for this intervention. The patient in this case had difficulty obtaining insurance and was lost to follow-up after surgical intervention; therefore, no additional treatments were performed.

\section{Conclusions}

This report presents a case of a very large neglected giant basal cell carcinoma, which was discovered upon workup of orthostatic lightheadedness and iron deficiency anemia. Although rare, basal cell carcinoma must be included on the differential of a large cutaneous lesion and may be a source of significant blood loss.

\section{References}

1. Randle HW, Roenigk RK, Brodland DG. Giant basal cell carcinoma (T3). Who is at risk? Cancer 1993;72:162430 .

2. Zoccali G, Pajand R, Papa P, et al. Giant basal cell carcinoma of the skin: literature review and personal experience. J Eur Acad Dermatol Venereol 
2012;26:942-52.

3. Vaca-Aguilera MR, Guevara-Gutiérrez E, Barrientos-García JG, Tlacuilo-Parra A. Giant basal cell carcinoma: clinicalhistological characteristics of 115 cases. Int J Dermatol 2019;58:1430-4.

4. Desmond B, Boudreaux L, Young J. A rare case of super giant basal cell carcinoma. JAAD Case Rep 2015;1:280-2.

5. Archontaki M SS, Korkolis DP, Arnogiannaki N, et al. Giant Basal cell carcinoma: clinicopathological analysis of 51 cases and review of the literature. Anticancer Res 2009;29:2655-63.

6. Laageide L, Wendl E, Wadle J, Powers J. Symptomatic iron deficiency anemia from neglected giant basal cell carcinoma. JAAD Case Rep 2020;6:1019-23.

7. Hudson E, Abu Hilal M. Super giant basal cell carcinoma in an autistic patient: A case report. SAGE Open Med Case Rep 2020;8:2050313X20939481.

8. Andersen RM, Lei U. A massive neglected giant basal cell carcinoma in a schizophrenic patient treated successfully with vismodegib. J Dermatolog Treat 2015;26:575-6.

9. de Bree E, Laliotis A, Manios A, et al. Super giant basal cell carcinoma of the abdominal wall: still possible in the $21 \mathrm{st}$ century. Int J Dermatol 2010;49:806-9.

10. Holzbauer M, Groß S, Huemer GM, et al. Giant basal cell carcinoma including focal squamous cell carcinoma of the buttock: A rare case. Dermatol Ther 2020;33:e13674.

11. Di Lorenzo S, Zabbia G, Corradino B, et al. A rare case of giant basal cell carcinoma of the abdominal wall: excision and immediate reconstruction with a pedicled deep inferior epigastric artery perforator (DIEP) flap. Am J Case Rep 2017;18:1284-8.

12. Snow SN, Sahl W, Lo JS, et al. Metastatic basal cell carcinoma. Report of five cases. Cancer 1994;73:328-35.

13. Sahned J, Mohammed Saeed D, Misra $\mathrm{S}$, et al. Giant ulcerative basal cell carcinoma with local metastasis: a case report and assessment of surgical techniques. Cureus 2019;11:e6426.

14. Wollina U, Bayyoud Y, Krönert C, Nowak A. Giant epithelial malignancies (Basal cell carcinoma, squamous cell carcinoma): a series of 20 tumors from a single center. J Cutan Aesthet Surg 2012;5:12-9.

15. Sekulic A, Migden MR, Oro AE, et al. Efficacy and safety of vismodegib in advanced basal-cell carcinoma. N Engl
J Med 2012;366:2171-9.

16. Vornicova O, Bar-Sela G. Rapid response to vismodegib in a patient with advanced basal cell carcinoma. JAAD Case Rep 2015;1:267-8.

17. Orduz Robledo M, Lebas E, Reginster MA, et al. Giant morphea-form basal cell carcinoma of the umbilicus: Successful debulking with vismodegib. Rare Tumors 2018;10:2036361318 772938.

18. Koekelkoren FHJ, Roodbergen SL, Baerveldt EM, et al. Vismodegib for giant, locally advanced, basal cell carcinoma and its complex position in clinical practice. JAAD Case Rep 2019;5:267-70.

19. Hoorens I, Vossaert K, Ongenae K, Brochez L. Is early detection of basal cell carcinoma worthwhile? Systematic review based on the WHO criteria for screening. Br J Dermatol 2016;174: 1258-65.

20. Wolfe CM, Green WH, Cognetta AB, Hatfield HK. Basal cell carcinoma rebound after cessation of vismodegib in a nevoid basal cell carcinoma syndrome patient. Dermatol Surg 2012;38: 1863-6. 